EESTI NSV TEADUSTE AKADEEMIA TOIMETISED. XVII KÖIDE

KEEMIA * GEOLOOGIA. 1968, Nr. 1

ИЗВЕСТИЯ АКАДЕМИИ НАУК ЭСТОНСКОЯ ССР. ТОМ ХVII

ХИМИЯ * гЕОЛОГИя. 1968, № 1

X. KECСEJ

\title{
ФОРМИРОВАНИЕ ОЗЕР НА ПОДНИМАЮЩЕМСЯ ПОБЕРЕЖЬЕ ЭСТОНИИ
}

Озера Эстонии можно классифицировать по разным принципам: характеру и генезису озерных впадин, возрасту и т. д.

По характеру и генезису озерные впадины подразделяются на (Kask, 1964): 1) прегляциальные (напр., Чудское озеро), 2) гляциальные (напр., озеро Саадъярв), 3) прибрежные (напр., озера Кяэсла), 4) болотные и окнищевые (напр., озеро в болоте Нигула), 5) искусственные (напр., Нарвское водохранилище). Имеется в Эстонии и своеобразное озеро Каали, образовавшееся на месте падения крупного метеорита.

Большинство из 1114 озер Эстонии (Kask, 1964) образовались гляциальным путем. Территориально они распределены неравномерно, что объясняется разнообразием доледникового и ледникового рельефа. Бо́льшая часть озер Эстонии (около 2/3) расположена в возвышенной Эстонии, в то время как обширные районы низменной Эстонии почти лишены их.

В настоящей статье ограничимся рассмотрением только прибрежных озер в пределах разновозрастных озерно-морских террас низменной Эстонии.

Территория низменной Эстонии в поздне- и послеледниковое время неоднократно подвергалась трансгрессиям вод разных стадий Балтийского моря, следы деятельности которых прослеживаются в виде разновозрастных аккумулятивно-абразионных террас (Орвику, 1955; Кессел, 1961 и др.). Из-за неравномерного неотектонического поднятия земной коры эти террасы в северо-западной части Әстонии шире, чем в юго-западной и северо-восточной частях Эстонии (рис. 1). В настоящее время насчнтывается около 100 прибрежных озер (Kask, 1964). Во время распространения Анцилового озера и Литоринового моря (в раннем и среднем гологене) в Западной Әстонии (в том чнсле и на острове Сааремаа) озер было значнтельно больше, чем сейчас.

Приступая к рассмотрению условий формирования, развития, возраста и длительности существования прибрежных озер, необходимо отметить, что образование их во многом предопределялось коренным и ледниковым рельефом Эстонин. Здесь нередки озера, образовавшиеся в небольших бессточных впадинах и ложбинах ледникового (озера Румму, Руйла и Ярвеотса в Северной Эстонии) или коренного рельефа (озера Вяэна и Тылинымме в анциловой стадии). Но большинство озер па озерно-морских террасах возникло все же вследствие запруживания их прибрежными аккумулятивными образованиями Балтийского моря.

Образовались прибрежные озера в разное время. Наиболее древние из них возникли в X фазе развития лесов по Нильсону (Nilsson, 1935), т. е. во время существования Балтийского приледникового озера 


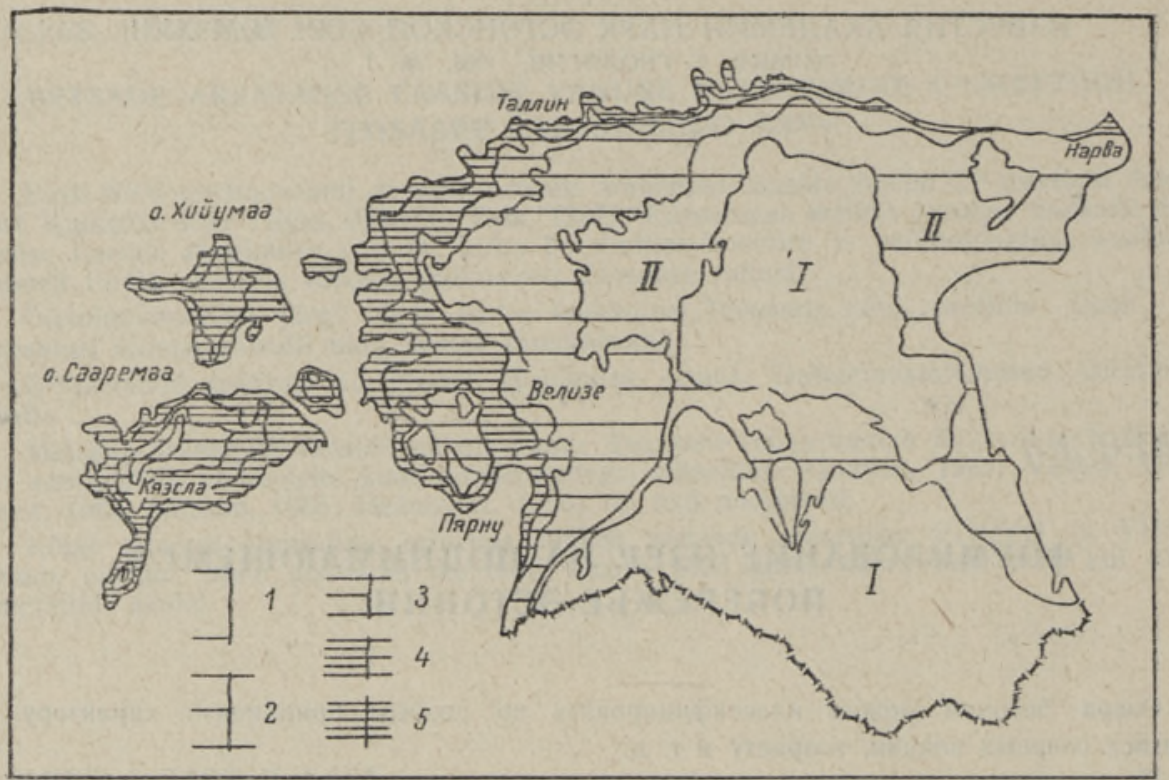

Рис. 1. Поздне- и послеледниковые береговые линии и соответствующие озерно-морские террасы:

1 - граница максимального распространения разновозрастных местных прнледннковых озер; 2 - граница максимального распространения Балтийского приледникового озера; 3 - граннца максимального распространения Анцилового озера; 4 - граниша максимального распространення Литоринового моря; 5 - граница макснмального распространения Лимниевого моря. I - возвышенная Эстоння, II - ннзменная Эстония.

(например, бывшие озера Вырусоо и Хагери). Некоторые из них существуют и в настоящее время. Наиболее молодые прибрежные озера встречаются в Северо-Западной Эстонии, в Перакюла, Ноароотси и на южном берегу о. Сааремаа. Образование их началось в I фазе развития лесов.

Прибрежные озера в Эстонии небольшие. Площадь их в большинстве случаев составляет лишь $1-2 \kappa м^{2}$ и только в редких случаях превышает $20 \kappa \mu^{2}$, например, в пределах современного болота Лээкова близ Нарвы. Глубины их чаще всего тоже невелики - обычно несколько метров, максимально до $10 \mathrm{~m}$.

В развитии прибрежных озер Эстонии наблюдается известная цикличность (так наз. полный и неполный циклы). Первой фазой полного цикла развития прибрежных озер является фаза эмбриональной лагуны, за которой следуют фазы лагуны, лагунного озера и прибрежного озера. Впоследствии озера зарастают и переходят в болотные равнины. В фазе эмбриональной лагуны определенная часть моря (крупного озера) отделяется от свободной акватории либо подводными аккумулятивными формами, либо недоросшими надводными аккумулятивными образованиями, либо выступами коренного или ледникового рельефа, вследствие чего она уже не вполне свободно сообщается с морем. При дальнейшем росте аккумулятивных береговых форм или понижении уровня воды в условиях регрессии сообщение с морем становится еще слабее, приводит к образованию лагуны. Лагунная фаза в узком смысле кончается полным отчленением лагуны от моря. Между фазами лагуны и прибрежного озера можно еще выделить кратковременную фазу лагунного озера, у которой видимая связь с основным водоемом отсутствует и проникновение морских вод может осуществляться лишь путем фильтрации через отделяющие лагуну береговые отложения или пере- 
плескиванием штормовых волн. В фазе прибрежного озера связь с морем уже полностью отсутствует.

Хорошим примером полного цикла развития прибрежных водоемов является озеро Кяэсла анциловой стадии на єосточном склоне Центральной возвышенности о. Сааремаа (Кессел, Раукас, 1967). Вследствие трансгрессии Анцилового озера в окрестностях Кяэсла во второй половине VIII фазы развития лесов возникли условия, приведшие к образованию эмбриональной лагуны, в которой отлагались глинистые алевриты. В это же время началось формирование косы Кяэсла, которая питалась вдольбереговым потоком наносов юго-восточного направления. На границе между VIII и VII фазами развития лесов дистальная часть косы достигла противостоящего берега, полностью отделив таким образом от Анцилового озера озерный водоем. В начале VII фазы развития лесов в последнем отлагались алевритовые глины (соответствуют фазе лагунного озера). В фазе прибрежного озера происходит сокращение площади лагунного озера, накопляется озерная известь (до конца VII фазы развития лесов). Затем начинается отложение сапропеля. K максимуму III фазы развития лесов прибрежное озеро Кяэсла заросло окончательно.

Если при трансгрессии бассейна затопляется ранее существовавшее озеро, лагуна или болото, то под отложениями полного цикла развития прибрежных водоемов могут залегать отложения предшествующего цикла или отдельных фаз последнего. Примерами такого рода могут служить местонахождения Вяэна (Кессел, 1963), Ярвесоо, Казесоо, Кихельконна и др. (Мянниль, 1963).

Хорошим соответствующим примером может служить также озеро Велизе анциловой стадии (Кессел, Раукас, 1967). Қ западу от современного верхового болота Велизе, находящегося между Аравере и Палази (Юго-Западная Эстония), расположена коса Тапу, образовавшаяся при трансгрессии Анцилового озера. Под отложениями этой косы во время анциловой трансгрессии погребена залежь древесно-тростникового торфа и темно-серая алевритовая глина с прослойками гипнового торфа. Возраст торфа по пыльцевому анализу соответствует максимуму VIII фазы развития лесов (Кессел, 1963). Возраст покрывающей торф темно-серой алевритовой глины по пыльцевому анализу соответствует второй половине VIII фазы развития лесов. Торф и глина прослеживаются под отложениями верхового болота Велизе на протяжении приблизительно $700 \mu$ к востоку.

Образование и возраст фаз развития озера Велизе по данным пыльцевого анализа (рис. 2) можно себе представить следующим образом:

1. На месте болота Тапу, которое существовало на доанциловой прибрежной равнине примерно 9000 лет тому назад (залежь $A$ ), в начале анциловой трансгрессии после максимума VIII фазы развития лесов образовалась эмбриональная лагуна, где накапливались глинистые отложения с небольшим содержанием растительных остатков (главным образом линзы гипнового торфа) и мелких створок Pisidium sp. (залежь Б).

2. При стабилизации уровня в ходе анциловой трансгрессии наступают фазы лагуны и лагунного озера. Накапливаются алевритовые глины, в нижней части которых встречаются прослойки тростникового торфа. В верхней части этой залежи значительно увеличивается содержание органического вещества (залежи $B$ и $\Gamma$ ).

3) В конце VIII фазы развития лесов образуется фаза прибрежного 


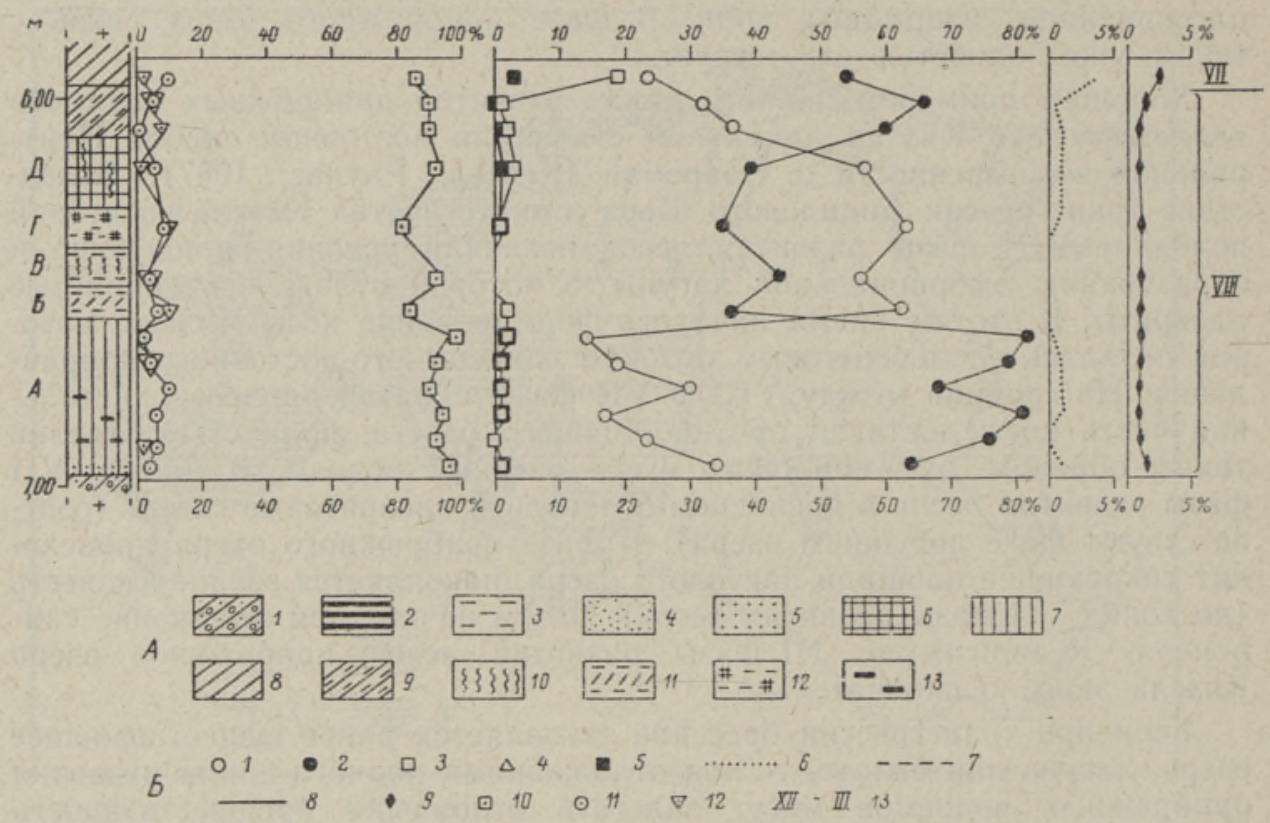

Рис. 2. Пыльцевая диаграмма нижней части верхового болота Велизе.

A. Грунты к виды органогенных отложепий: $t$ - морена, 2 - ленточная глина, 3 - глина. 4 - песок, 5 - гравия̆, 6 - сапропель, 7 - древесный торф, 8 - осоковый торф, 9 - гипновоосоковый торф, 10 - остатки тростников, 11 - глнна с прослойками гипнового торфа, 12 - глина, обогащенная органическим веществом, $13-$ куски древесины.

Б. Пыльца древесных и недревесных пород: 1 - березы, 2 - сосны, 3 - ольхи, 4 - ели. 5 сумма пыльцы широколиственных лород. 6 - вяза, 7 - липы, 8 - дуба, 9 - орешника, $10-$ сумма пыльцы древесных пород и кустарников, 11 ... сумма пыльщы травяннстых растениї, 12 - споры, 13 - фазы развития лесов по Нильсону.

озера. Соответствующие отложения представлены сапропелем с остатками тростников (залежь Д).

4. Начало образования болота Велизе совладает с началом анциловой регрессии (граница между VIII и VII фазами развития лесов). Соответствующие отложения в нижней части разреза представлены, по определению Х. Курм, гипново-осоковым торфом. Развитие этого болота продолжается и в настоящее время.

Смена рассматриваемых фаз в развитии прибрежных водоемов хорошо прослеживается также в пределах современного болота Иыэляхтме (Кессел, Раукас, 1967). Разрез Йэляхтме начинается слоем гравийного песка, который образовался в заливе во время трансгрессии Анцилового озера. Вверх по разрезу пески заменяются алевритами, содержащими зеленые водоросли (соответствует собственно лагунной фазе), а потом - алевритами, содержащими раковины субфоссильных озерных моллюсков (соответствуют фазам лагунного и прибрежного озер).

Аналогично происходило развитие озер литоринового возраста Қыйвасоо (о. Хийумаа) и Люманда (о. Сааремаа), где фазы эмбрионального озера и лагуны слабо развиты, но Зато очень четко наблюдаются фазы лагунного и прибрежного озер. В нижней части этих разрезов встречаются тонкие слои (до 5 см) глинистого сапропеля с полупресноводными диатомовыми водорослями Литоринового моря, на которых залегает сапропель с примесью тростникового торфа. Последний слой также маломощный (обычно менее $50 \mathrm{~cm}$ ). 

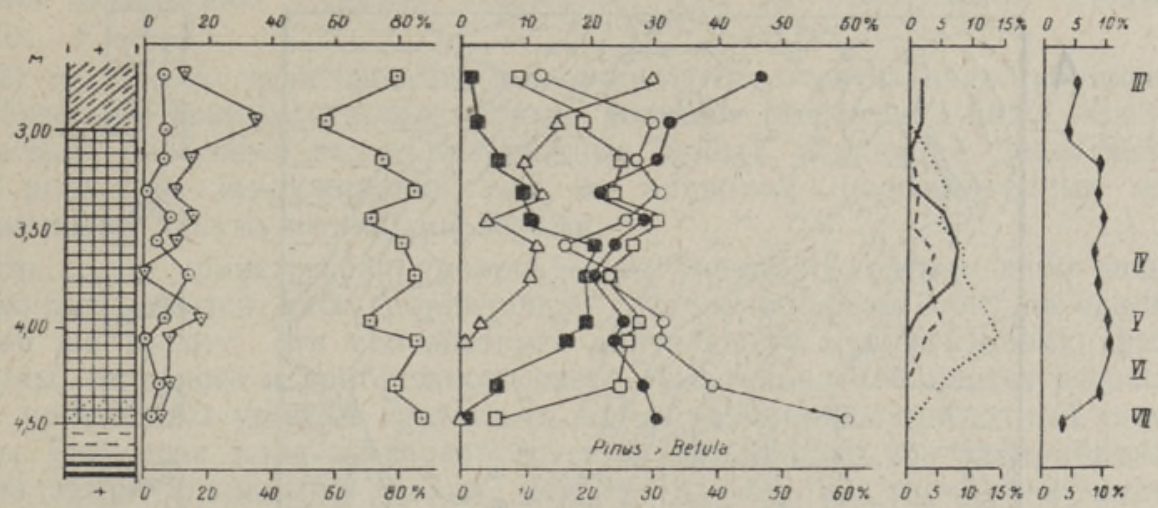

Рис. 3. Пыльщевая диаграмма нижней части верхового болота Кахала. Условные обозначення см. на рнс, 2.

В вышеуказанных случаях береговые процессы непосредственно влияют на возникновение и развитие прибрежных озер. Неполный цикл развития прибрежных озер наблюдается тогда, когда воды моря (крупного озера), например Литоринового моря, Анцилового озера и др., непосредственно не затопляют озерный водоем, а последний образуется под влиянием запруживания прибрежными образованиями. Морская вода в этом случае может попасть в озерный водоем только путем фильтрации через прибрежные отложения. Поэтому здесь не встречаются фазы эмбриональной лагуны и лагуны, а наблюдаются лишь фазы прибрежного или лагунного озер, прибрежного озера и, наконец, болото.

Примером развития таких прибрежных озер могут служить озера Кахала (Северная Эстония), Вальгеярв (Северо-Западная Эстония) (Кессел, Раукас, 1967), Пелисоо (о. Сааремаа) и др., образовавшиеся в условиях анциловой трансгрессии. В нижней части соответствующих разрезов отложения представлены озерной известью, возраст которой начало VII фазы развития лесов (рис. 3). Аналогично образовались прибрежные озера Нийтвялья (Северная Эстоння) (Кессел, 1960) и Сибула (близ г. Пярну) (Кессел, 1963) во время литориновых трансгрессий в VI и V фазах развития лесов. В этих разрезах соответствующие отложения представлены озерным сапропелем.

Хорошим примером неполного цикла развития прибрежиых водоемов является также заросшее озеро Хара в предглинтовой полосе Северной Эстонии. Прибрежное озеро в пределах современного верхового болота Хара запружено во время первой литориновой трансгрессии $\left(\mathrm{L}_{\mathrm{I}}\right)$. Об этом свидетельствует озерный сапропель, возраст которого соответствует VI фазе развития лесов (рис. $4, \bar{E}$ ). Абсолютный возраст нижней части этого сапропеля по методу $\mathrm{C}^{14} 7080 \pm 75$ лет (Лийва, Ильвес и Пуннинг, 1966). Прибрежный водоем Хара начал свое существование с фазы лагунного озера, о чем говорит наличие в нижней части сапропеля тонких прослоек песка. Уже к V фазе развития лесов прибрежное озеро Хара заросло.

В юго-западной части полуострова Хара, к западу от описанного озера, встречается целая серия разновозрастных «дочерних» лагунных и прибрежных озер, отделенных друг от друга многочисленными береговыми барами отступавшего Литоринового моря (рис. $4, A$ ). Это узкие, вытянутые в меридиональном направлении водоемы. Озерные отложения в них маломощные и представлены, главным образом, сапропелем с примесью тростникового торфа. 


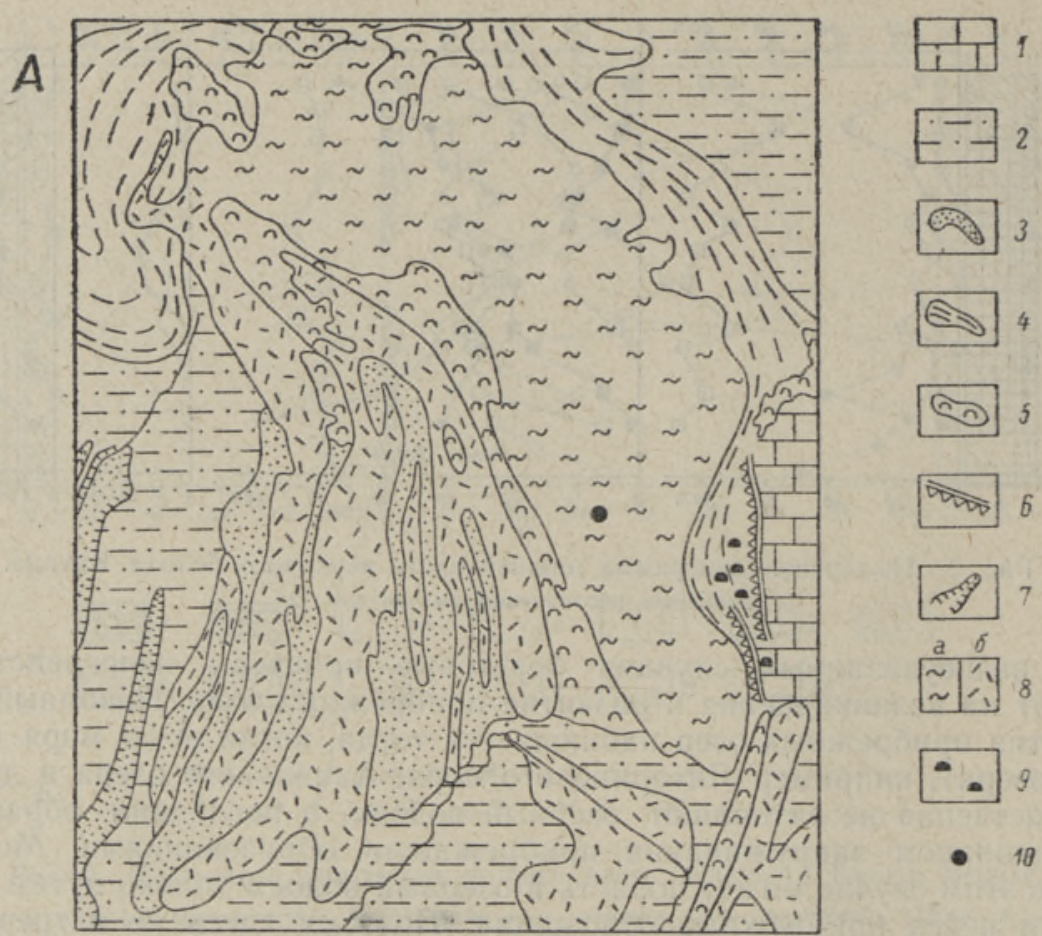

E

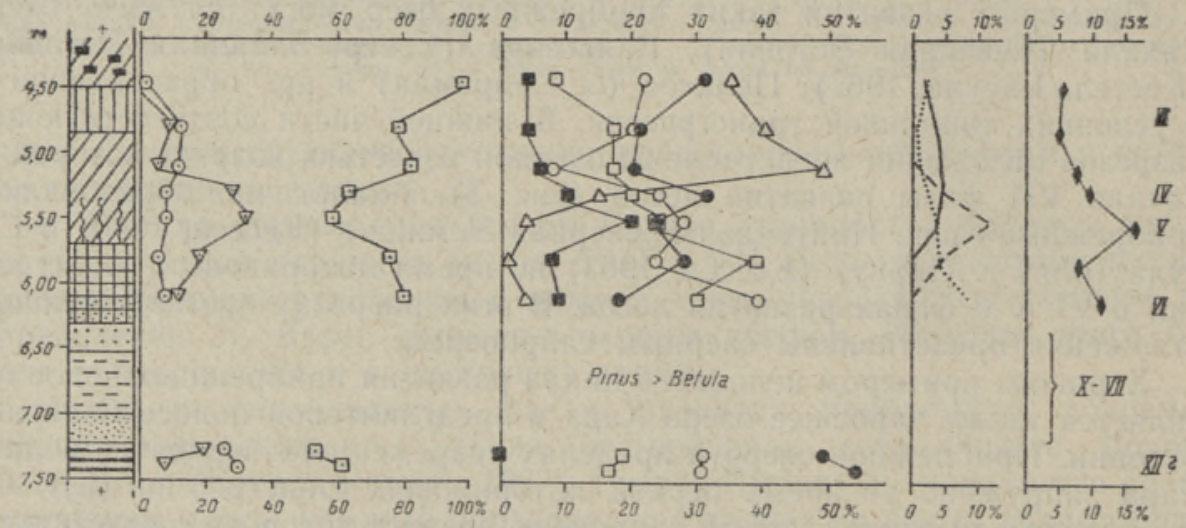

Рис, 4. $A$, Схема распространення баров и заболоченных лагун Литоринового моря в юго-западной части полуострова Хара:

1 - альвары, 2 - морские равнины (алевриты), 3 - береговые бары, 4 - береговые валы.

5 - прибрежные дюны. 6 - уступы, 7 - долины, 8 - верховые $(a)$, низннные (б) болота, 9 - накопления эрратических валунов, 10 - место ручного бурения.

Б. Пыльцевая диаграмма нижней части верхового болота Хара. Условные обозначения см. на рнс. 2.

В условиях трансгрессии моря (крупного озера) имеются более благоприятные предпосылки для образования прибрежных водоемов, чем в условиях регрессии моря (крупного озера). Это обусловлено тем, что:

1) во время трансгрессии уровень моря (крупного озера) поднимается и затопляет определенные части суши или по меньшей мере обуслов- 
ливает повышение уровня подземных вод на прибрежной полосе суши;

2) во время трансгрессии накапливаются относительно крупные прибрежные аккумулятивные формы рельефа (береговые бары, косы, пересыпи, береговые валы, прибрежные дюны), играющие существенную роль при запруживании вод во впадинах, расположенных за названными аккумулятивными телами.

Во время трансгрессии уровень моря (крупного озера) либо медленно поднимается, либо сравнительно длительное время стоит на одной и той же высоте. Это способствует длительному существованию фаз лагуны, лагунного и прибрежного озер. Как только начинается регрессия, понижается уровень грунтовых вод и улучшается природный сток воды. Регрессия моря не способствует запруживанию вод за прибрежными аккумулятивными телами, которые к тому же характеризуются небольшими размерами.

Известно много прибрежных озер, образовавшихся во время трансгрессий Анцилового озера и Литоринового моря, но до сих пор не установлено ни одного прибрежного озера, которое образовалось бы во время регрессии Анцилового озера. Нам известно только одно прибрежное озеро (заросшее озеро Клоога), которое образовалось во время регрессии Литоринового моря. Больше известно озер, образовавшихся во время регрессии Лимниевого моря (например, озера Хиндасте, Вескиярв, Тянавярв, Энглама, Лохья, Койги и др.). Это объясняется главным образом тем, что регрессия Лимнневого моря продолжалась значительно дольше (максимально 4500 лет), чем регрессии Анцилового озера и Литоринового моря. Кроме того, понижение уровня воды во время лимниевой стадии происходило медленнее, чем во время анцилового и литориновой стадий, что обусловлено общим замедлением неотектонического поднятия земной коры.

\section{Л ИТЕРАТ У РА}

Кессел Х. Я., 1960. О геологии голоценовых береговых образований Балтийского моря на территории Эстонской ССР, Тр. Ин-та геол. АН ЭССР, т. V, Таллин.

Кессел Х. Я., 1961. Древние береговые образования бассейна Балтийского моря в Эстонской ССР, Тр. Ин-та геологин АН ЭССР, т. VIII, Морские берега, Таллин.

Кессел Х. Я., 1963. Возраст трансгрессий голоценовых бассейнов Балтики в Эстонии по палинологическим данным, В сб.: «Балтика», вып. 1. Вильнюс. Кессел Х. Я., Р аукас А. В., 1967. Прибрежные отложения Анцилового озера и Литоринового моря в Эстонии, Таллин.

Л и й в а А., И льв в е с Э., П унн и нг Я.-М., 1966. Список радиоуглеродных датировок Института зоологни и ботаники Академии наук Эстонской ССР, Изв. АН ЭССР, Сер. бнол., 15, № 1.

М янниль Р. П., 1963. Залежи озерной кзвести на острове Сааремаа, их малакофауна и возраст. Тр. Ин-та геол. АН ЭССР, т. ХII, Таллин.

О рв и ку К. К., 1955. Основные черты геологического развития территории Эстонской ССР в антропогеновом периоде, Изв. АН ЭССР, 4, № 2.

K a s k J., 1964. Eesti järvede nimestik, Tartu.

Nilss o n T., 1935. Die pollenanalytische Zonengliederung der spät- und postglazialen Bildungen Schonens, Geol. Fören. Förhandl., Bd. 57.

Ннститут геологии

Академии наук Эстонской ССР
Поступила в редакцию 7/VI 1967 


\section{H. KESSEL}

\section{JARVEDE KUJUNEMINE EESTI KERKIVAL RANNIKUL}

Rannikujärved asuvad Balti mere erivanuselistel akumulatsiooniterrassidel MadalEestis (joon. 1). Need järved on kujunenud hilisjääajast nüüdisajani seoses Balti mere vanade veekogude transgressioonide ja regressioonidega.

Meie kerkival rannikul on käesoleva töö autor eristanud rannikujärvede arenemise täieliku ja ebatäieliku (lühendatud) tsükli. Täielikus tsüklis on esimesteks faasideks embrüonaalne laguun ja laguun, millele järgnevad laguunse järve ja rannikujärve faasid, nagu see esines, näit. Kääsla ja Velise (joon. 2) vanade rannikujärvede puhul. Ebatäielikus tsüklis puuduvad kaks esimest faasi, näit. Kahala (joon. 3) ja Hara (joon. 4) vanade rannikujärvede arenemisel.

Rannikujärvede arenemise täielikus tsüklis avaldub rannikuprotsesside otsene mōju Balti mere vee sissetungimise näol kujuneva järvenōo piiresse; ebatäieliku tsükli rannikujärv on vaid üles paisutatud vanade rannikumoodustiste poolt.

Rannikujärvede kujunemise tingimused on olnud kōige soodsamad Balti mere vanadel transgressioonidel, millal toimus arvukate ja suurte akumulatiivsete rannikumoodustiste kuhjumine. Nende järvede kujunemise tingimused olid vähem soodsad aeglaste regressioonide puhul, näit. limnea staadiumil, ja kõige vähem soodsad suhteliselt kiirete regressioonide puhul, näit. Antsülusjärve ja Litoriinamere regressioonil.

\section{H. KESSEL}

\section{SEENBILDUNG AN DER SICH HEBENDEN KOSTE VON ESTLAND}

Küstenseen finden sich auf Akkumulationsterrassen verschiedenen Alters in NiederEstland, in der küstennahen Zone der Ostsee (Abb. 1). Die Entstehung dieser Seen fällt in die Periode von der späten Eiszeit an und bis in die Jetztzeit, in Verbindung mit Transgressionen und Regressionen der Ostsee.

An der sich hebenden Küste Estlands unterscheidet der Verfasser einen vollständigen und einen nicht vollständigen (verkürzten) Zyklus der Entwicklung von Küstenseen. Im vollständigen Zyklus sehen wir als erste Phasen die embryonale Lagune und die Lagune, worauf die Phasen des Lagune-Sees und des Küstensees folgen, wie es bei den alten Küstenseen Kääska und Velise (Abb. 2) der Fall ist. In dem nicht vollständigen Zyklus fehlen die zwei ersten Phasen, - so bei der Entwicklung der alten Küstenseen Kahala (Abb. 3) und Hara (Abb. 4).

Im vollständigen Zyklus der Entstehung von Küstenseen zeigt sich der direkte Einíluß der Küstenprozesse darin, daB das Wasser der Ostsee in die Grenzen des entstehenden Seebeckens dringt; beim unvollständigen Zyklus wird der Küstensee durch alte Küstenbildungen abgestaut.

Die Entstehungsbedingungen der Küstenseen waren am günstigsten während der alten Transgressionen der Ostsee, als zahlreiche große akkumulative Küstenbildungen angehäuft wurden. Weniger günstig waren diese Bedingungen bei langsamen Regressionen, so z. B. im Stadium des Limneameeres, und am wenigsten günstig bei relativ schnell verlaufenden Regressionen, - z. B. bei der Regression des Ancylussees und aer des Litorinameers. 